\title{
REVOLUÇÕES, INCOMENSURABILIDADE E RACIONALIDADE Científica nos Escritos TARdios DE ThOMAs KuHN
}

\author{
TAMires DAL MAGRO
}

\begin{abstract}
Kuhn continued producing very high quality philosophy after The structure of scientific revolutions (1962) until his death in 1996. This paper describes the changes his thought underwent regarding three theses: (1) that scientific development is not cumulative, (2) that paradigms are incommensurable, and (3) that the choice of new paradigms in periods of revolution is not based solely on observations and logical reasoning. These three theses were the subject of controversies in the initial reception of Kuhn's work, motivating strong criticisms of the image of science allegedly defended by author. In response to those criticisms Kuhn emphasized the realistic aspect of his philosophy and reformulated in more linguistic terms theses (1) and (2), but he left unchanged thesis (3). We argue that the changes introduced in (1) and (2) rendered Kuhn's views more accurate and less comprehensive, and that thesis (3) was remained inadequately developed.
\end{abstract}

Keywords: Kuhn; scientific revolutions; incommensurability; scientific rationality.

\section{Introdução}

A estrutura das revoluções científicas (Kuhn 1962; doravante: Estrutura) é amplamente considerada um divisor de águas na história da filosofia da ciência. Além de romper com alguns padrões de análise que predominaram na filosofia da ciência da primeira metade do século vinte, que tendiam a privilegiar discussões e abordagens abstratas e metodológicas, mostrou, talvez definitivamente, que qualquer concepção adequada da ciência tem de levar em conta também a sua história. ${ }^{1}$ Na sua caracterização da atividade científica, Kuhn defendeu diversas teses que foram particularmente influentes na literatura posterior. Destacaremos aqui três delas: (1) a tese de que o progresso da ciência não é cumulativo, mas contém rupturas fundamentais, chamadas de 'revoluções científicas'; (2) a tese de que teorias de diferentes paradigmas científicos são incomensuráveis; e (3) a tese de que a avaliação e escolha de hipóteses científicas não é guiada somente por critérios lógicos e observacionais - especialmente nos períodos revolucionários. No que diz respeito a essa terceira tese, Kuhn afirma que as decisões científicas podem sofrer influência de elementos subjetivos como a capacidade de persuasão dos defensores de uma hipótese ou a sua aceitabilidade prévia no interior de uma comunidade científica. Elementos sociais e psicológicos internos à comunidade científica podem justapor-se a critérios lógicos e observacionais de escolha. Ilustrações disso podem ser encontradas em diversos textos de Kuhn. ${ }^{2}$ Em um livro publicado alguns anos antes da Estrutura, narrando

Principia 17(1): 183-216 (2013).

Published by NEL — Epistemology and Logic Research Group, Federal University of Santa Catarina (UFSC), Brazil. 
episódios da chamada 'Revolução Copernicana', Kuhn já dizia que um dos fatores que persuadiu Galileu da teoria heliocêntrica era de natureza estética, e não dizia respeito a vantagens preditivas ou explicativas. A teoria original de Copérnico não se adequava melhor às observações do que a teoria geocêntrica da época:

[...] como o próprio Copérnico reconheceu, a verdadeira atração da astronomia centrada no Sol era mais estética do que pragmática. Para os astrônomos, a escolha inicial entre o sistema de Copérnico e o de Ptolomeu só podia ser uma questão de gosto. [...] No entanto, como a própria Revolução Copernicana indica, questões de gosto não são desprezíveis. O ouvido preparado para discernir a harmonia geométrica podia detectar uma nova pureza e coerência na astronomia de Copérnico centrada no Sol, e se essa pureza e coerência não tivessem sido reconhecidas, podia não ter havido nenhuma Revolução.

Já examinamos uma das vantagens estéticas do sistema de Copérnico. Ele explica a principal característica qualitativa do movimento planetário sem usar epiciclos. [...] Mas só astrônomos que valorizassem mais a clareza qualitativa do que a exatidão quantitativa (e houve alguns - Galileu entre eles) podiam considerar este um argumento convincente em face do complexo sistema de epiciclos e excêntricos elaborado no De Revolutionibus. (Kuhn 1957, p.188-189).

Kuhn põe em relevo o fato de que o sistema copernicano pareceu para muitos mais harmonioso, coerente e natural. Essa percepção, no entanto, não agradava necessariamente a todos os astrônomos, uma vez que "novas harmonias não aumentam exatidão ou simplicidade" (1957, p.197), mas pode e de fato agradou a

aquele subgrupo de astrônomos matemáticos, limitado e talvez irracional, cujo ouvido neoplatônico para as harmonias matemáticas não podia ser obstruído por página após página de matemática complexa levando finalmente a predições numéricas dificilmente melhores do que aquelas que tinham conhecido antes. (Kuhn 1957, p.197)

Foram observações de cunho histórico como essas que levaram Kuhn à concepção de ciência que encontramos sistematizadas na Estrutura. As três teses mencionadas acima - a de que há revoluções científicas (progresso não cumulativo), a de que paradigmas são incomensuráveis e a de que elementos não observacionais e extralógicos podem afetar uma escolha científica — foram objeto de grande controvérsia na recepção inicial da obra de Kuhn nas décadas de 1960 e 1970. Um registro disso pode ser encontrado em diversos textos da época, entre eles a coletânea $A$ crítica e $o$ desenvolvimento do conhecimento. ${ }^{3}$ Autores influentes como Popper e Lakatos acusaram explicitamente a abordagem kuhniana de ser relativista, psicologista, dogmática e irracionalista. ${ }^{4}$ Lakatos (1979 [1970]) chegou a dizer que a imagem que Kuhn tem 
da ciência é sociopsicológica: a escolha entre teorias rivais não passaria de uma questão de psicologia das multidões, e o que tornaria aceitável uma revolução científica seria uma espécie de conversão mística. Sobre os conceitos de 'crise' e 'revolução', Lakatos diz:

Emerge então um novo "paradigma", incomensurável com o seu predecessor. Não existem padrões racionais para a sua comparação. Cada paradigma contém seus próprios padrões. A crise leva embora não só as velhas teorias e regras, mas também os padrões que nos fizeram respeitá-las. O novo paradigma traz uma racionalidade totalmente nova. Não há padrões superparadigmáticos. A mudança é um efeito de adesão de última hora. Assim sendo, de acordo com a concepção de Kuhn, a revolução científica é irracional, uma questão da psicologia das multidões. (Lakatos 1970b, p.220-1)

Em linhas parecidas, Popper é igualmente crítico das concepções de Kuhn, dizendo que no período de 'ciência normal', o cientista aparece como essencialmente a-crítico dos fundamentos que movem a pesquisa:

A meu ver, o cientista 'normal', tal como Kuhn o descreve, é uma pessoa da qual devemos ter pena. [...] O cientista 'normal', a meu juízo, foi mal ensinado. Acredito, e muita gente acredita, como eu, que todo o ensino de nível universitário (e se possível de nível inferior) devia consistir em educar e estimular o aluno a utilizar o pensamento crítico. O cientista 'normal', descrito por Kuhn, foi mal ensinado. Foi ensinado com espírito dogmático: é uma vítima da doutrinação. (1979, p.65)

Popper também considera a concepção de ciência kuhniana como relativista:

Kuhn sugere que a racionalidade da ciência pressupõe a aceitação de um referencial comum. Sugere que a racionalidade depende de algo como uma linguagem comum e um conjunto comum de suposições. Sugere que a discussão racional e a crítica racional só serão possíveis se estivermos de acordo sobre questões fundamentais.

Essa é uma tese amplamente aceita e, com efeito, está na moda: a tese do relativismo. (Popper 1979, p.69)

Essa leitura de Kuhn como relativista ou irracionalista é influente ainda hoje. Friedman (2009 [2000]), por exemplo, afirma que Kuhn coloca em questão a racionalidade da ciência e erra o alvo quando defende a racionalidade do conhecimento científico com a noção de valores (ver mais sobre isso na seção 3 abaixo): "paradigmas sucessivos, em uma revolução científica [...] não compartilham nenhuma base que permite a comunicação racional mútua" (p.198). O problema identificado por Friedman tem origem na sua interpretação da tese da incomensurabilidade: se paradigmas são incomensuráveis, então não seriam intercomunicáveis. 
Nos textos posteriores à Estrutura, Kuhn mostrou-se bastante insatisfeito com essas interpretações. ${ }^{5}$ Chegou a dizer que não passariam de mal-entendidos: "não entendo agora o que meus críticos querem dizer quando empregam termos como 'irracional' e 'irracionalidade' para caracterizar meus pontos de vista” (Kuhn 1979 [1970], p.327). Diversos filósofos "disseram que minhas concepções fazem da escolha de teorias 'uma questão de psicologia das massas'. [...] Afirmações como essas manifestam um completo mal-entendido" (2009 [1977], p.340). Kuhn dedicou boa parte de sua obra posterior à reformulação e esclarecimento de suas concepções de maneira a responder ou evitar essas objeções. Neste artigo, destacaremos as obras de Kuhn que tratam diretamente das três teses mencionadas acima, no intuito de rastrear as reformulações do seu pensamento após a Estrutura, mostrando como ele responde ou tenta evitar as críticas provocadas pela sua descrição inicial de tais conceitos em sua obra tardia. Como veremos, as reformulações tardias das três teses acima tenderam a enfatizar os aspectos linguísticos dos conceitos em questão e o aspecto realista de seu pensamento. Isso tornou algumas de suas teses mais precisas e menos abrangentes. Ocorreu o que alguns chamam de 'virada linguística': o conceito de paradigma foi substituído pelo de léxico estruturado, as crises passam a ser entendidas como colapsos de linguagem no léxico de uma comunidade científica, as revoluções passam a ser entendidas como a substituição de um léxico (ou de parte de um léxico) por outro, e a incomensurabilidade passou a ser caracterizada em termos de intraduzibilidade parcial. Nos três casos é visível uma ênfase nos aspectos linguísticos; o próprio Kuhn chama atenção para isso: "se eu estivesse reescrevendo agora a Estrutura, enfatizaria mais a mudança de linguagem e menos a distinção normal/revolucionário" (2006d, p.76). No entanto, em relação à racionalidade das escolhas científicas, Kuhn mantém nos escritos tardios uma concepção ainda muito próxima da que formulou na Estrutura. Como veremos (na seção 3), das três teses mencionadas acima, essa foi a que menos desenvolvimentos recebeu na obra tardia de Kuhn, embora contenha insights bem perspícuos sobre as escolhas de teorias rivais em períodos revolucionários.

O presente artigo contém três seções: a primeira centra-se no conceito de revolução científica tal como foi concebido inicialmente por Kuhn e nas reformulações que sofreu nas obras posteriores; a segunda e terceira seções fazem o mesmo com relação às teses de Kuhn sobre incomensurabilidade e escolhas científicas, respectivamente.

\section{Revoluções científicas}

O conceito de revolução científica foi introduzido por Kuhn para salientar os aspectos não cumulativos do desenvolvimento da ciência. A história da ciência, ele diz, contém rupturas teóricas que marcam a emergência de novos paradigmas: novos

Principia 17(1): 183-216 (2013). 
conjuntos de problemas, métodos, objetos e práticas são adotados, que nem sempre fazem sentido no paradigma anterior. Isso não significa, no entanto, que jamais haja progresso cumulativo na ciência. No que diz respeito às predições de observações, certamente há progresso cumulativo ao longo do tempo, e mesmo ao longo de sucessivas revoluções: as observações passadas via de regra não são descartadas. ${ }^{6}$ Há uma distinção importante em Kuhn entre rupturas teóricas e acúmulo de resultados e observações. Essa diferença é explicada por Kuhn já em A revolução copernicana:

É assim que a ciência avança: cada novo esquema conceitual abrange os fenômenos explicados pelos seus predecessores e acrescenta-lhes algo.

Mas embora as realizações de Copérnico e Newton sejam permanentes, os conceitos que tornaram essas realizações possíveis, não o são. Só a lista de fenômenos explicáveis é que cresce; não existe processo cumulativo semelhante para as explicações em si. Conforme a ciência progride os seus conceitos são repetidamente destruídos e substituídos [...] (1957, p.280)

\subsection{O conceito de revolução científica na Estrutura}

Na Estrutura, Kuhn apresentou as revoluções científicas como períodos na história de uma disciplina científica. O esquema geral para o desenvolvimento histórico de uma disciplina seria este: período pré-paradigmático, ciência normal, crise e revolução (ciência extraordinária), novamente ciência normal, crise e revolução, e assim por diante. Kuhn descreve a pesquisa no período pré-paradigmático como dispersa e desestruturada: várias escolas de pensamento competem entre si, cada uma com suas concepções próprias acerca da natureza fundamental dos fenômenos investigados, bem como dos métodos, instrumentos e critérios de avaliação e interpretação das observações. ${ }^{7}$ O desaparecimento dessas divergências fundamentais só ocorre quando um dos grupos concorrentes consegue produzir um exemplar ou uma notável realização científica capaz de atrair a maioria dos praticantes de uma área de investigação, criando assim o que se pode chamar de uma "disciplina" científica, que é então guiada por um modelo teórico e prático unificado. Isso é o que Kuhn chama na Estrutura de o estabelecimento de um paradigma. ${ }^{8}$ Há passagens na Estrutura que sugerem explicitamente que há somente um único paradigma por disciplina: "Qual é a natureza dessa pesquisa mais especializada e esotérica permitida pela aceitação de um paradigma único por parte do grupo?” (p.43; itálicos acrescentados). ${ }^{9}$ A aceitação do paradigma implica o direcionamento da pesquisa científica para a articulação dos fenômenos e teorias já fornecidos pelo paradigma (ver Estrutura, cap. 1).

Um paradigma é composto, de maneira geral, por leis expressamente declaradas e suposições teóricas, modos-padrão de aplicar essas leis fundamentais e resolver problemas, instrumentação e técnicas instrumentais, além de princípios metafísicos muito gerais (uma maneira de ver a natureza), ${ }^{10}$ recomendações metodológicas e 
compromissos intelectuais, institucionais e mesmo pessoais. ${ }^{11}$ Uma vez estabelecido o paradigma, um modelo impõe-se para a comunidade daquela disciplina, que diz quais problemas são relevantes e quais métodos e soluções são aceitáveis.

Kuhn denominou o período histórico de uma disciplina científica em que a pesquisa é governada por um paradigma de 'ciência normal'. Esse período caracteriza-se pela investigação e solução de "enigmas" ou "quebra-cabeças" (puzzles) que aparecem no interior das teorias daquele paradigma. ${ }^{12}$ Essa caracterização de Kuhn da prática científica enfatiza, portanto, não a busca de uma representação ou imagem verdadeira da realidade, mas a resolução de problemas. ${ }^{13}$ A aceitabilidade de uma hipótese depende da resolução satisfatória de problemas considerados relevantes pela comunidade científica, e não necessariamente de algum tipo de conformidade ou adequação à realidade como às vezes se supôs nas tradições realistas ou metafísicas. ${ }^{14}$ A solução de problemas e a explicação dos fenômenos naturais é, segundo Kuhn, cumulativa nos períodos de ciência normal, e nesse sentido há avanços científicos mensuráveis. Em qualquer período da ciência, no entanto, há fenômenos que as teorias aceitas não conseguem explicar: as chamadas 'anomalias'. Em alguns períodos as anomalias tornam-se de tal modo numerosas e variadas que parecem não ter como ser resolvidas sem revisões nos fundamentos das teorias vigentes. Nesses casos, a confiança da comunidade científica na capacidade explicativa do modelo vigente tende a diminuir, produzindo um afrouxamento do paradigma sobre as convicções predominantes na comunidade científica, o que pode levar a um período de crise, em que começam a surgir novas teorias e modelos teóricos incompatíveis com o antigo paradigma. A crise aprofunda-se quando aparecem escolas de pensamento rivais sobre os fundamentos da disciplina, cada uma buscando persuadir a comunidade científica como um todo. Nesses períodos, conjeturas e especulações filosóficas passam a ser particularmente relevantes para as discussões no interior da comunidade científica. ${ }^{15}$

Nos períodos de crise e revolução, elementos subjetivos tornam-se mais influentes nas escolhas científicas. Critérios de escolha lógicos ou observacionais deixam de ser suficientes ou determinantes. Disso não se segue que as escolhas científicas desses períodos sejam arbitrárias, pois são balizadas por valores herdados da prática normal anterior que continuam atuando sobre a comunidade durante os períodos extraordinários (ver Estrutura, cap. 11). Entre os valores mencionados por Kuhn estão a simplicidade de uma hipótese ou teoria, o potencial percebido dessa hipótese ou teoria para resolver novos problemas (isto é, sua fecundidade), ou mesmo elementos ideológicos e psicológicos que possam inclinar os membros da comunidade por um certo tipo de teoria em detrimento de outras. ${ }^{16}$ Sobre esse ponto, Kuhn afirma que não há como impor um conjunto de regras ao comportamento individual do cientista adequado aos casos concretos que encontrará. Por essa razão, o procedimento científico deve ser explicado levando em conta a natureza do grupo científico e o 
que ele valoriza (ver Estrutura, p.293 ss.). Como veremos a seguir, no entanto, esse permaneceu um tema pouco explorado na filosofia de Kuhn. Seus comentários são quase todos programáticos e não chegam a elaborar em detalhes uma explicação de como valores científicos efetivamente afetam ou determinam as escolhas.

Em relação ao progresso científico, na Estrutura Kuhn apresenta uma analogia com a evolução das espécies. O processo de desenvolvimento científico não é um processo de evolução em direção a algo (ver nota 13), mas "um processo de evolução a partir de um início primitivo - processo cujos estágios sucessivos caracterizam-se por uma compreensão sempre mais refinada e detalhada da natureza" (Estrutura, p.215). Assim como no progresso evolucionário apresentado por Darwin em $A$ origem das espécies, em que "não há um objetivo posto de antemão por Deus ou pela natureza", mas sim "a seleção natural [...] responsável pelo surgimento gradual, mas regular, de organismos mais elaborados, mais articulados e muito mais especializados" (p.216-7), o progresso científico pode ser entendido como estágios sucessivos de um processo de desenvolvimento "marcados por um aumento de articulação e especialização do saber científico" (p.217). Esse processo "pode ter ocorrido, como no caso da evolução biológica, sem o benefício de um objetivo preestabelecido, sem uma verdade científica permanente fixada, da qual cada estágio do desenvolvimento científico seria um exemplar mais aprimorado" (p.217).

De modo geral, essa é a apresentação e desenvolvimento inicial de Kuhn do conceito de revolução científica. Como sabemos, algumas passagens da Estrutura levaram alguns autores a perceber Kuhn como um relativista em ciência. As seguintes foram particularmente provocativas desse tipo de reação: após uma revolução, "os cientistas adotam novos instrumentos e orientam seu olhar em novas direções" e passam a ver "coisas novas e diferentes quando, empregando instrumentos familiares, olham para os mesmos pontos já examinados anteriormente" (Estrutura, p.147); "na medida em que seu único acesso a esse mundo dá-se através do que veem e fazem, poderemos ser tentados a dizer que, após uma revolução, os cientistas reagem a um mundo diferente" (p.148). A percepção dos cientistas é modelada por um paradigma, que "é um pré-requisito para a própria percepção. O que um homem vê depende tanto daquilo que ele olha como daquilo que sua experiência visual-conceitual prévia o ensinou a ver" (p.150). Assim,

[...] em períodos de revolução, quando a tradição científica normal muda, a percepção que o cientista tem de seu meio ambiente deve ser reeducada — deve aprender a ver uma nova forma (gestalt) em algumas situações com as quais já estava familiarizado. Depois de fazê-lo o mundo de suas pesquisas parecerá, aqui e ali, incomensurável com o que habitava anteriormente. (Estrutura, p.148)

De fato, há ambiguidade nessas passagens que podem levar a interpretações de Kuhn como relativista, como de fato ocorreu. Negando interpretações desse tipo, e 
com o intuito de responder ou evitar tais críticas, Kuhn dedicou-se a reformular e tornar mais preciso o conceito de revolução científica, bem como o conceito de paradigma, desfazendo as ambiguidades presentes nas formulações iniciais e enfatizando o aspecto realista de suas concepções, como veremos nas seções seguintes.

\subsection{Reformulações do conceito de revolução científica no Kuhn tardio}

Nos escritos posteriores, Kuhn admite haver um traço metafórico nas suas apresentações iniciais da noção de revolução científica: "usei muito o duplo sentido, visual e conceitual, do verbo 'ver' e reiteradamente, equiparei mudanças de teoria a mudanças de gestalt" (2006a, p.49). Esse uso metafórico de algumas palavras permite diferentes interpretações das suas teses, e em particular a que atribui a ele concepções relativistas. Em "O que são revoluções científicas?" (2006a), Kuhn rejeita essas leituras, e explica suas próprias concepções dizendo que as hipóteses elaboradas após uma revolução nem sempre podem ser adequadamente descritas na linguagem da disciplina anterior à revolução. As mudanças revolucionárias

[...] envolvem descobertas que não podem ser acomodadas nos limites dos conceitos que estavam em uso antes de elas terem sido feitas. A fim de fazer ou assimilar uma tal descoberta, deve-se alterar o modo como se pensa, e se descreve, algum conjunto de fenômenos naturais. (2006a, p.25)

Note-se que nessa descrição Kuhn evita falar (como fizera na Estrutura) de mudanças de mundo ou no mundo, restringindo-se a falar de mudanças no pensamento que se tem sobre o mundo ou nas descrições que se fazem dele. As alterações revolucionárias não se limitam ao que é previsto pelas teorias em questão, mas afetam também a ontologia da ciência e o modo como se pensa e se descrevem os objetos, bem como a prática científica (métodos, instrumentos, comportamentos dos cientistas etc.). Nesse mesmo artigo, Kuhn destaca três características do que ele entende por mudança revolucionária na ciência:

i) Mudanças revolucionárias são holísticas, no sentido de que afetam a rede conceitual inteira da disciplina ou subdisciplina em questão, bem como o modo como os cientistas percebem seus objetos e os instrumentos que usam. Por exemplo, "no caso da física aristotélica, não se pode simplesmente descobrir que o vácuo é possível ou que o movimento é um estado, e não uma mudançade-estado; uma imagem integrada de vários aspectos da natureza tem de ser mudada ao mesmo tempo" (Kuhn 2006a, p.41). Nessas mudanças o que ocorre não é somente uma revisão ou acréscimo em alguma hipótese ou lei anterior enquanto o resto da teoria permanece inalterado. Esse tipo de mudança mais localizada pode e de fato ocorre em períodos não-revolucionários, ou de 'ciência normal', como Kuhn diz. Na mudança revolucionária, ao contrário, são

Principia 17(1): 183-216 (2013). 
vários enunciados gerais (hipóteses, leis etc.) inter-relacionados que são revisados, e isso acaba gerando alterações globais na teoria e prática da ciência.

ii) O modo como os termos científicos ligam-se com seus referentes muda - na Estrutura, Kuhn falava de mudança de 'significado'. Essa mudança altera não somente os critérios pelos quais os termos ligam-se à natureza, mas a distribuição dos objetos em categorias. Alteram-se as categorias taxonômicas usadas para as descrições e generalizações científicas. Isso implica em uma redistribuição dos objetos em novas categorias, que são interdefinidas. Os exemplos que foram "paradigmáticos de movimento para Aristóteles — da bolota para o carvalho, ou da doença para a saúde - não eram, de modo algum, movimentos para Newton" (2006a, p.42.). Na mudança do paradigma aristotélico para o newtoniano "uma família natural deixou de ser natural; seus membros foram redistribuídos entre conjuntos preexistentes; e apenas um deles continuou mantendo o nome antigo" (p.42). A mudança revolucionária, portanto, está arraigada "na natureza da linguagem, pois os critérios relevantes para a categorização são, ipso facto, os critérios que ligam os nomes dessas categorias ao mundo" (p.43).

iii) Muda o "modelo, metáfora ou analogia" usado pelos cientistas. Em outras palavras, alteram-se os padrões de similaridade e diferença entre tipos de fenômenos. Na física de Aristóteles, "a pedra que cai era como o carvalho que cresce ou como a pessoa convalescente de uma doença" (2006a, p.43). Padrões de similaridade como este colocam fenômenos diferentes na mesma categoria taxonômica. Esses padrões são ensinados aos estudantes das respectivas disciplinas científicas por meio de exemplos concretos exibidos por pessoas que já os reconhecem - algo que às vezes Kuhn chama de "exemplares" (ver, por exemplo, o Posfácio da Estrutura, p.234 ss.). Em períodos de revolução, esses padrões de similaridade e as metáforas que os acompanham são substituídos. Sem esses padrões e metáforas, a linguagem científica não tem como ser adquirida adequadamente, pois é por meio deles que se aprende a conectar os termos científicos aos fenômenos naturais percebidos. Em boa parte do aprendizado da linguagem, o conhecimento das palavras e o conhecimento da natureza são adquiridos conjuntamente. Na verdade, esta é uma das principais características reveladas pelas revoluções científicas: o conhecimento da natureza mostra-se inseparável da própria linguagem que expressa esse conhecimento. Assim, "a violação ou distorção de uma linguagem científica anteriormente não problemática é a pedra de toque para a mudança revolucionária" (2006a, p.45).

Essas três características compõem a concepção tardia de Kuhn sobre revoluções científicas. Ela difere do que encontramos na Estrutura, pois Kuhn deixa de falar de 
revoluções como mudança de paradigmas e passa a falar de revoluções como alteraç̃oes nas categorias taxonômicas de uma comunidade científica. Ao substituir a noção de paradigma pela noção de categoria taxonômica ou estrutura lexical, Kuhn fornece uma caracterização única desse conceito, ao contrário da noção de paradigma na Estrutura, que foi caracterizada de maneiras diversas. ${ }^{17}$ Por isso, pode-se dizer que as caracterizações que Kuhn fornece das noções de categoria taxonômica e de estrutura lexical são mais precisas e evitam as ambiguidades resultantes da sua formulação inicial de paradigma, como veremos na próxima seção.

\subsection{Reformulações no conceito de paradigma depois da Estrutura}

A concepção inicial de 'paradigma' foi substituída por Kuhn já no Posfácio da Estrutura (escrito em 1969 e publicado em 1970) pelas noções de 'matriz disciplinar' e 'exemplar'. Uma matriz disciplinar é composta por quatro elementos: o conjunto de regras, leis e fórmulas explicitamente partilhadas pela comunidade científica; o conjunto de crenças em determinados modelos; os próprios exemplares; e, por fim, os valores dessa comunidade. Este último componente é "mais amplamente partilhado por diferentes comunidades do que as generalizações simbólicas ou modelos" (Estrutura, p.231). A importância particular dos valores "aparece quando os membros de uma comunidade determinada precisam identificar uma crise, ou mais tarde, escolher entre maneiras incompatíveis de praticar sua disciplina" (p.231). Os valores citados por Kuhn são a capacidade de resolução de quebra-cabeças, a simplicidade, a coerência interna, a plausibilidade e a compatibilidade com teorias disseminadas no momento.

Os exemplares, por sua vez, referem-se ao conjunto de fenômenos, problemas e soluções-padrão que instruem os aprendizes de uma ciência (transmitidos ostensivamente e com auxílio de manuais durante os períodos de formação do cientista) e guiam os cientistas em períodos de ciência normal. Um exemplar apresenta uma certa maneira de perceber certos fenômenos e de agir diante deles que não tem como ser apreendida senão mediante a exibição de casos concretos. Esse elemento é o que Kuhn considera mais importante da antiga noção de paradigma. Diferente da noção de 'matriz disciplinar', ele dificilmente se deixa formular por meio de regras explícitas, e por isso pode parecer não ser adequadamente captado pela noção de léxico desenvolvida nos escritos tardios de Kuhn.

Nos escritos tardios, Kuhn deixa de falar em 'matriz disciplinar' e 'exemplares' e passa a falar de alterações 'taxonômicas', ou ainda em alterações nas 'estruturas lexicais'. Ele explica que léxico ou estrutura lexical refere-se "ao módulo no qual membros de uma comunidade linguística armazenam os termos para espécie dessa comunidade" (2006b, p.281). Termos para espécies (ou termos taxonômicos) são as categorias necessárias para a descrição de mundo, "uma categoria ampla que in-

Principia 17(1): 183-216 (2013). 
clui espécies naturais, espécies artificiais, espécies sociais, e provavelmente outras" (2006c, p.117). Esses termos para espécie estão submetidos a uma limitação que Kuhn chama de princípio de não-superposição, que é definido da seguinte forma: "não é possível que dois termos para espécies, dois termos que rotulem espécies, possam superpor-se no que diz respeito aos seus referentes" (2006c, p.118). Kuhn ilustra esse princípio dizendo que "não há cães que também sejam gatos, nem anéis de ouro que também sejam de prata, e assim por diante: isso é o que faz com que cães, gatos, prata e ouro, sejam, cada um deles, uma espécie" (ibid.). Quando algum desses termos superpõe-se a outros - por exemplo, se se encontram cães que também são gatos —, é preciso refazer parte da taxonomia, e esse é um dos fatores centrais que pode provocar uma mudança de léxico (ou seja, uma revolução).

Quanto aos exemplares, nos textos tardios Kuhn enfatiza seu papel na aprendizagem de termos científicos. Como afirma o autor, no processo de aprendizagem, os termos científicos não são definidos simplesmente, mas introduzidos pela exposição a exemplos de seu uso: "essa exposição frequentemente inclui apresentações reais, por exemplo, num laboratório para estudantes, de uma ou mais situações exemplares a que os termos em questão são aplicados por alguém que já sabe usá-los. [...] Os termos são ensinados por meio da apresentação, direta ou descritiva, de situações às quais eles se aplicam." (Kuhn 2006d, p.87). Ainda sobre esse ponto, ressalta Kuhn que em todas as áreas da ciência

[...] estabelecer o referente de um termo para espécies naturais requer exposições não somente a membros variados dessa espécie, mas também a membros de outras - isto é, a indivíduos aos quais o termo poderia ser erroneamente aplicado. Apenas por meio da multiplicidade de tais exposições é que o estudante pode adquirir [...] o espaço de características [feature space] e o conhecimento de relevância requeridos para ligar a linguagem ao mundo. (Kuhn 2006f, p.246)

A substituição do conceito de paradigma pelo conceito de léxico estruturado e o princípio de superposição que o acompanha indica o que Kuhn pode ter querido dizer na Estrutura por 'mudança de mundo' acarretada por uma revolução científica (ver as passagens da Estrutura, p.147 e p.148, citadas acima). Se termos para espécie definidos por uma estrutura lexical são pré-requisitos para descrição do mundo, então uma mudança lexical — acarretada pela violação do princípio de superposição - implicará em uma mudança na forma como os membros da comunidade científica descrevem o mundo. Com a mudança lexical, os membros de uma comunidade "descreverão o mundo de maneira diferente e farão generalizações diferentes a respeito dele" (Kuhn 2006b, p.285). Assim, as mudanças revolucionárias são concebidas como mudanças nos léxicos que descrevem o mundo e não como mudanças no mundo mesmo. No entanto, como não temos acesso ao mundo senão por meio de léxicos, uma mudança no léxico acarreta uma mudança no modo como o mundo 
é concebido e percebido. Isso parece evitar as interpretações relativistas das teses de Kuhn de que após uma revolução haveria mundos distintos, e como veremos na seção seguinte, nos escritos tardios Kuhn defende um aspecto realista de suas teses.

\subsection{Aspectos realistas dos escritos tardios de Kuhn}

A nova formulação da noção de revoluções científicas e paradigma evita algumas das ambiguidades mencionadas acima contidas no texto original da Estrutura e torna mais explícita uma inclinação realista do pensamento de Kuhn. Esse realismo, no entanto, é de um tipo particular, e distinto do realismo científico da filosofia tradicional. Kuhn formula-o em termos de um 'kantismo pós-darwiniano':

Como as categorias kantianas, o léxico fornece as precondições da experiência possível. Mas as categorias lexicais, ao contrário de suas predecessoras kantianas, podem mudar e mudam, tanto com o passar do tempo quanto com a passagem de uma comunidade a outra. É claro que nenhuma dessas mudanças jamais é vasta. Estejam as comunidades em questão deslocadas no tempo ou no espaço conceitual, suas estruturas lexicais devem coincidir em grande parte, ou não poderiam existir cabeças-de-ponte que permitissem a um membro de uma delas adquirir o léxico da outra. Assim também, na ausência de grande superposição, não seria possível para os membros de uma única comunidade avaliar novas teorias propostas quando sua aceitação demandasse uma mudança lexical. [...]

É óbvio que, subjacente a todos esses processos de diferenciação e mudança, precisa haver algo permanente, fixo e estável. Porém, como a Ding an sich de Kant, esse algo é inefável, indescritível, não-analisável. (Kuhn 2006c, p.131-2)

Os léxicos seriam, assim, constitutivos da experiência possível do mundo; cada léxico torna acessível um conjunto particular de mundos possíveis (que se superpõem em grande parte, mas jamais por completo), mas não ditam quais experiências teremos ao adotá-lo. Eles são

[...] constitutivos do âmbito infinito de experiências possíveis que poderiam concebivelmente ocorrer no mundo real ao qual dão acesso. Quais dessas experiências concebíveis ocorrem nesse mundo real é algo que precisa ser aprendido tanto da experiência cotidiana quanto da experiência mais sistemática e refinada que caracteriza a prática científica. Ambas as experiências são mestras rigorosas, resistindo firmemente à promulgação de crenças inadequadas à forma de vida permitida pelo léxico. (Kuhn 2006b, p.299-300)

Kuhn (2006f) compara suas concepções com as de Richard Boyd, afirmando que ambos são realistas convictos, mas que ele (Kuhn) tem uma concepção diferente sobre o significado de 'realismo':

Principia 17(1): 183-216 (2013). 
Concebida como um conjunto de instrumentos para resolver quebra-cabeças técnicos em áreas selecionadas, a ciência ganha claramente em precisão e alcance com a passagem do tempo. Como instrumento, a ciência indubitavelmente progride. Contudo, as afirmações de Boyd não se referem à eficácia instrumental da ciência, porém, mais apropriadamente, à sua ontologia, àquilo que realmente existe na natureza, às articulações reais do mundo. E, nessa área, não vejo nenhuma evidência histórica para um processo de aproximação. Como sugeri em outro lugar, a ontologia da física relativística é, em aspectos significativos, mais semelhante à da física aristotélica do que à da newtoniana. (p.253)

Kuhn afirma ter um "desconforto" em relação a pontos de vista como os de Boyd, para o qual mundo é "o mundo real único, ainda desconhecido, mas em direção ao qual a ciência avança por aproximações sucessivas” (p.253). Em relação a esse tipo de realismo científico, Kuhn formula as seguintes reservas:

O que é o mundo, pergunto, caso não inclua a maioria dos tipos de coisas a que se refere a língua real falada em determinada época? Seria a Terra realmente um planeta no mundo de astrônomos pré-copernicanos que falavam uma linguagem na qual as características relevantes do referente do termo 'planeta' excluíam sua atribuição à Terra? Faria mais sentido óbvio falar em acomodar a linguagem ao mundo do que acomodar o mundo à linguagem? Ou seria o modo de falar que cria essa distinção, ela própria ilusória? Seria aquilo a que nos referíamos como 'o mundo' talvez o produto de uma própria acomodação mútua entre experiência e linguagem? (p.253)

E conclui, dizendo:

O mundo de Boyd com suas articulações parece-me, como as coisas-em-si de Kant, em princípio, incognoscível. A perspectiva para a qual me aproximo também seria kantiana, mas sem coisas-em-si e com categorias da mente que poderiam mudar com o tempo, à medida que a acomodação da linguagem e experiência prosseguem. Uma perspectiva desse tipo não precisa, penso eu, tornar o mundo menos real. (p.253)

O ponto é que os léxicos são condições para as experiências no mundo, e portanto daquilo que dizemos ser real. $\mathrm{O}$ fato de vários léxicos terem sido historicamente possíveis não implica que aquilo que dizemos por seu intermédio não possa ser verdadeiro do mundo. Não temos nenhum acesso ao mundo senão por meio de algum léxico e, portanto não faria sentido (não teríamos critérios de correção ou adequação) falar de um 'mundo real' na ausência de algum léxico: a própria noção de ser real supõe algum tipo de distinção entre o que é real e o que é ilusório (não-real), e isso só pode ser feito se temos à disposição as categorias apropriadas para fazer essa discriminação. O realismo científico que Kuhn defende tem presente uma relação de acomodação mútua entre linguagem e experiência. Nosso acesso ao mundo sempre 
é estruturado por um léxico, mas isso não implica que o mundo dependa de um léxico para existir: o léxico condiciona as experiências que se pode ter do mundo, uma certa classificação daquilo que podemos experimentar do mundo, caso apliquemos a ele aquele léxico. Mas a não aplicação do léxico não implica que o mundo não possa ser concebido daquela maneira, ou que aquela concepção não possa ser objetiva. As características que o mundo tem quando concebido sob um léxico não deixam de existir se o léxico deixa de ser aplicado (como ocorre após uma revolução), da mesma maneira que um objeto não deixa de ser verde na ausência de seres com aparatos visuais capazes de ver essa cor. $^{18} \mathrm{Na}$ mudança de um léxico para outro, as descrições do mundo se modificam, isto é, o mundo tal como concebido pelo cientista muda e, com isso, a maneira de acessá-lo. Há portanto, um sentido em que podemos ser tentados a dizer, como Kuhn sugeriu, que o mundo em que o cientista vive após uma revolução parece não ser mais o mesmo. Mas disso não se segue que tenha havido alguma alteração nos objetos descritos pelo cientista.

\subsection{Progresso científico nos escritos tardios de Kuhn}

Além de enfatizar a analogia do progresso científico com a evolução das espécies já apresentada nos capítulos finais da Estrutura, nos textos tardios Kuhn introduz um outro aspecto do progresso científico através das revoluções científicas. Na época em que escreveu a Estrutura, as revoluções eram descritas como "episódios no desenvolvimento de uma ciência ou especialidade científica isolada, episódios que [...] descuradamente, [foram comparados] a mudanças de Gestalt e descritos como envolvendo mudanças de significado" (Kuhn 2006b, p.305). Nos textos tardios, esses episódios são descritos como aqueles em que velhas espécies são removidas e novas espécies são introduzidas; são pensados como episódios transformadores no desenvolvimento de ciências individuais e são vistos como desempenhando um segundo papel fundamental:

[...] são, com frequência, e talvez sempre, associados a um aumento no número de especialidades científicas requeridas para a aquisição continuada de conhecimento científico. Esse ponto é empírico, e a evidência, uma vez verificada, é esmagadora: o desenvolvimento da cultura humana, incluindo-se o das ciências, tem sido caracterizado [...] por uma vasta e cada vez mais acelerada proliferação de especialidades. Esse padrão é aparentemente um prérequisito para o desenvolvimento continuado do conhecimento científico. A transição para uma nova estrutura lexical, para um conjunto revisado de espécies, permite a resolução de problemas que a estrutura prévia era incapaz de lidar. Mas o domínio da nova estrutura é, normalmente, mais restrito do que o da velha, às vezes muito mais restrito. O que fica fora dele torna-se o domínio de uma outra especialidade científica, na qual permanece em uso uma forma desenvolvida com base nas velhas espécies. A proliferação de es-

Principia 17(1): 183-216 (2013). 
truturas, práticas e mundos é o que preserva a amplitude do conhecimento científico; a prática intensa nos horizontes dos mundos individuais é o que aumenta sua profundidade. (Kuhn 2006b, p.306) ${ }^{19}$

Dessa forma, as revoluções científicas parecem fundamentais para a ampliação do conhecimento científico, uma vez que "é a especialização resultante da diversidade lexical que permite às ciências, vistas em conjunto, resolver os quebra-cabeças suscitados por um domínio de fenômenos naturais mais amplo do que uma ciência lexicalmente homogênea poderia alcançar" (Kuhn 2006c, p.126). A diversidade lexical resultante dos episódios revolucionários seria, assim, um pré-requisito essencial para o progresso no desenvolvimento científico. Mas, como vimos acima, a noção de progresso não deve ser entendida como uma aproximação a uma realidade independente de qualquer teoria, mas como algo instrumental: uma capacidade global ampliada de resolução de problemas e explicação de fenômenos.

\subsection{Alguns resultados das reformulações de Kuhn para os conceitos de paradigma e revolução científica}

As novas formulações de Kuhn para as noções associadas à revolução científica trouxeram mais precisão a suas teses e permitiram que ele respondesse ou evitasse algumas objeções suscitadas pelas formulações iniciais presentes na Estrutura. Substituir a noção de paradigma por léxico, tratar crise como um colapso de linguagem e revolução científica como mudança lexical, enfatizam as mudanças conceituais ou linguísticas presente em uma revolução. ${ }^{20}$ Essa ênfase trouxe uma caracterização unívoca para cada um desses conceitos, o que evita as ambiguidades que levaram a diferentes interpretações das teses de Kuhn. O conceito de paradigma na Estrutura foi tratado de modo bastante abrangente, o que dificultou a compreensão do que Kuhn estaria querendo dizer com tal noção (ver nota de rodapé 17). Já a definição de léxico estruturado parece evitar esse tipo de ambiguidade, uma vez que é tratado especificamente em termos de uma linguagem compartilhada pelos cientistas de uma comunidade, a qual contém termos para espécies distintas governadas por um princípio de não-superposição. O conceito de crise na Estrutura era caracterizado por uma perda de confiança da comunidade científica nos fundamentos da disciplina, acarretada pelo acúmulo de anomalias. Agora essa concepção é tratada como um colapso linguístico entre os membros de uma comunidade científica, acarretado pela violação do princípio de superposição. Idem para o conceito de revolução, não mais tratado como uma mudança de visão de mundo ou mudança de Gestalt — de forma que após uma revolução os cientistas trabalhariam em mundos diferentes - , mas como alterações lexicais, em que o que muda são os modos de descrever e acessar o mundo.

Principia 17(1): 183-216 (2013). 
Como veremos na seção seguinte, o conceito de incomensurabilidade desenvolvido nas obras tardias de Kuhn também é tratado em termos puramente linguísticos e, com isso, tem-se uma noção aparentemente mais fraca do que foi apresentado nas versões iniciais do conceito, na Estrutura.

\section{Incomensurabilidade}

Na Estrutura, Kuhn escreveu que um paradigma que orienta a pesquisa científica depois de uma revolução é incomensurável com os paradigmas anteriores. Haveria, então, com uma revolução, além de alterações conceituais, uma redefinição dos métodos, problemas relevantes e padrões de solução e de evidência aceitos numa disciplina:

[...] os paradigmas não diferem somente por sua substância, pois visam não apenas à natureza, mas também à ciência que os produziu. Eles são fonte de métodos, áreas problemáticas e padrões de solução aceitos por qualquer comunidade científica amadurecida, em qualquer época que considerarmos. Consequentemente, a recepção de um novo paradigma requer com frequência uma redefinição da ciência correspondente. Alguns problemas antigos podem ser transferidos para outra ciência ou declarados absolutamente "não-científicos". Outros problemas anteriormente tidos como triviais ou não-existentes podem converter-se, com um novo paradigma, nos arquétipos das realizações científicas importantes. À medida que os problemas mudam, mudam também, seguidamente, os padrões que distinguem uma verdadeira solução científica de uma simples especulação metafísica, de um jogo de palavras ou de uma brincadeira matemática. A tradição científica normal que emerge de uma revolução científica é não somente incompatível, mas muitas vezes verdadeiramente incomensurável com aquela que a precedeu. (Estrutura, p.137-8)

Algumas passagens da Estrutura parecem sugerir - esse, ao menos, foi o modo como Kuhn foi lido inicialmente - que teorias de paradigmas diferentes seriam incomparáveis, pois expressariam visões de mundo diferentes ou mesmo "mundos" diferentes, de tal modo que não haveria como escolher racionalmente entre elas - novamente, algo que foi lido como um elemento relativista do pensamento de Kuhn. Isso se seguiria do fato de as observações serem impregnadas teoricamente. ${ }^{21}$ Kuhn afirma, na Estrutura, que proponentes de paradigmas diferentes estão sempre comprometidos com estes paradigmas e não conseguem fazer contato completo com os pontos de vista uns dos outros. Isso se dá pela influência da incomensurabilidade acerca de três fatores: 1) defensores de paradigmas diferentes podem discordar acerca dos problemas que precisam ser resolvidos; 2) os padrões de solução de problemas não são os mesmos; e 3) dentro de um novo paradigma os velhos conceitos, termos e experiências se relacionam de maneira diferente. Por essas razões, diz

Principia 17(1): 183-216 (2013). 
Kuhn: "Em um sentido que eu sou incapaz de explicar melhor, os proponentes dos paradigmas competidores praticam seus ofícios em mundos diferentes" (Estrutura, p.192).

\subsection{Reformulações no conceito de incomensurabilidade nos escritos tardios de Kuhn}

Em escritos posteriores, Kuhn afirma que o conceito de incomensurabilidade foi um dos primeiros a motivá-lo a escrever a Estrutura, mas reconhece que mesmo antes dessa obra as tentativas de descrever a ideia central presente na noção eram "extremamente toscas" (Kuhn 2006b, p.280). Desde então, "esforços para compreendê-la e aprimorá-la têm sido minha preocupação central e cada vez mais obsessiva por trinta anos" (ibid.). Como veremos, as formulações tardias da noção de incomensurabilidade são mais fracas, por serem caracterizadas para grupos localizados de termos interdefinidos (e não para um paradigma com um todo, como na Estrutura). No artigo "Comensurabilidade, comparabilidade, comunicabilidade" (Kuhn, 2006d), Kuhn apresenta o que chama de 'incomensurabilidade local', que é caracterizada em termos da intraduzibilidade de algumas noções centrais e interdefinidas de um léxico para o vocabulário de outro léxico. Não haveria, nesses casos, uma linguagem comum para a qual duas teorias de léxicos diferentes possam ser traduzidas sem deixar resíduos ou perdas. ${ }^{22}$ Isso porque, "léxicos diferentes — os de diferentes culturas ou de diferentes períodos históricos, por exemplo — dão acesso a diferentes conjuntos de mundos possíveis, superpondo-se em grande parte, mas jamais por completo" (Kuhn 2006e, p.81).

No entanto, isso não implicaria incomparabilidade, pois seriam apenas alguns termos centrais de uma teoria que não poderiam ser traduzidos para o vocabulário de outra. A maioria dos termos, em particular boa parte dos termos diretamente ligados a fenômenos observáveis, seriam intertraduzíveis e funcionariam de maneira semelhante nas teorias em questão. Dessa maneira, poder-se-ia comparar duas teorias por meio das previsões de observações que cada uma faz. Essa é uma versão mais modesta da noção de incomensurabilidade do que supuseram boa parte dos críticos iniciais de Kuhn. Sobre esse ponto, há uma controvérsia sobre se houve ou não mudanças substanciais no pensamento de Kuhn. Howard Sankey (1993) sustenta que houve, e identifica três formulações distintas da tese da incomensurabilidade. Hoyningen-Huene (1993), no entanto, chama atenção para passagens do próprio Kuhn em que ele diz não ter havido mudanças substanciais, mas apenas no modo de expressá-lo. ${ }^{23}$

Para Sankey, houve um processo de transformação no conceito de incomensurabilidade, de tal modo que abordagem presente nos textos tardios "tem pouco em comum com a abordagem original" (1993, p.759). Inicialmente, 
[...] a noção de incomensurabilidade de Kuhn envolvia diferenças semânticas, metodológicas e observacionais entre teorias globais ou paradigmas. Sua discussão inicial sugeriu que proponentes de teorias incomensuráveis são incapazes de se comunicar, e que não há recurso à experiência neutra ou padrões objetivos para escolher entre teorias. Em esforços posteriores para esclarecer sua posição, ele [Kuhn] restringiu a incomensurabilidade para diferenças semânticas [...]. Nos últimos anos, começou a desenvolver a sua posição de forma mais refinada. Sua concepção atual é que há falha de tradução entre um aglomerado [cluster] localizado de termos interdefinidos dentro das linguagens das teorias. (1993, p.760, tradução nossa)

Segundo Sankey, a concepção de incomensurabilidade original de Kuhn "envolvia falhas de derivação [de teses de um paradigma para as teses de outro], 'mudanças de mundo' e mudanças globais [wholesale] de referência" (p.770). Na fase em que Sankey chama de fase de transição do conceito de incomensurabilidade, "incomensurabilidade implica falha de tradução exata entre teorias: termos de uma teoria têm significado que não podem ser expressos dentro da linguagem de outra teoria". No entanto, "Kuhn não fornece uma análise detalhada da falha de tradução entre as teorias durante esse período de transição. [...] [Somente] explica que a tradução é problemática, 'seja entre teorias ou linguagens', porque 'linguagens recortam o mundo de maneiras diferentes' " (1993, p.767). Nessa fase, Kuhn restringe a mudança de significado e referência a apenas alguns termos de teorias divergentes e, portanto, a falha de tradução é parcial. Disso segue-se

[...] que as teorias incomensuráveis compartilham um mínimo de vocabulário semanticamente invariante. Como resultado, não há nem mudança completa de referência, nem é o mundo independente da teoria sujeito à mudança. Assim, a imagem de Kuhn de 'mudança de mundo' pode ser interpretada como uma mudança nas 'categorias ontológicas' que diferentes teorias impõem sobre o mundo. (p.770)

O último desenvolvimento da noção de incomensurabilidade é a tese da incomensurabilidade local, que é apresentada como uma falha de tradução localizada entre conjuntos de termos interdefinidos. A tradução de certos termos locais falha porque o significado de tais termos é determinado em relação a outros termos interdefinidos do conjunto. Sobre esse desenvolvimento, diz Sankey:

[...] a tese da incomensurabilidade local não foi desenvolvida em detalhes e nem é claramente evidente na discussão kuhniana original da questão. Embora a tese local seja sugerida obliquamente durante seu período do meio, desenvolvimentos explícitos da versão local constituem mais um passo no processo de clarificação e refinamento que a abordagem de Kuhn de incomensurabilidade tem sofrido (p.772).

Principia 17(1): 183-216 (2013). 
O próprio Kuhn reconhece, no entanto, ao menos isto: que o uso da noção de incomensurabilidade na Estrutura era mais abrangente que seu uso tardio. Em particular, envolvia não apenas intraduzibilidade de alguns termos centrais interdefinidos de um léxico, mas também diferenças nos métodos, campo de problemas e padrões de solução, e afirma que "tais diferenças são consequências necessárias do processo de aprendizagem da linguagem" (Kuhn 2006d, p.48, nota 2).

\subsection{Críticas à noção tardia de incomensurabilidade}

Mesmo a nova formulação da noção de incomensurabilidade sofreu críticas: se não há como traduzir completamente teorias antigas para a linguagem moderna, então como é possível que um historiador da ciência, como o próprio Kuhn, reconstrua teorias antigas e as reapresente na linguagem contemporânea? Esse não seria, justamente, um caso de tradução ${ }^{24}$ Kuhn responde a essa crítica dizendo que para compreender um vocabulário novo ou desconhecido podemos ou traduzi-lo para nossa língua materna ou aprender a falar a outra língua. O que historiadores como ele próprio e outros fazem ao descrever teorias do passado é ensinar como aquela língua era falada (sobre isso, ver Sankey (1990)). Disso não se segue, no entanto, que os termos descritos sejam traduzíveis para o vocabulário da ciência contemporânea, nem que a teoria descrita pelo historiador seja por ele aceita ou adotada. Nas palavras de Kuhn:

[...] para compreender algum corpo de crenças científicas passadas, o historiador precisa adquirir um léxico que, aqui e ali, difere sistematicamente daquele corrente em sua própria época. Apenas usando esse léxico mais antigo pode ele traduzir acuradamente determinados enunciados que são básicos para a ciência sob investigação. Esses enunciados não são acessíveis por meio de uma tradução que use o léxico corrente, nem mesmo se o rol de palavras contidas for ampliado pelo acréscimo de termos selecionados, retirados de seu predecessor. (Kuhn 2006e, p.78)

Kuhn exemplifica esse ponto dizendo que termos como 'flogístico', 'elemento' e 'princípio' não têm como ser traduzidos para o vocabulário da química contemporânea. Isso porque

[...] eles constituem um conjunto inter-relacionado ou interdefinido que deve ser adquirido conjugadamente, num todo, antes que qualquer um deles possa ser usado e aplicado a fenômenos naturais. Apenas depois de terem sido adquiridos, alguém pode reconhecer a química do século XVIII pelo que ela era, uma disciplina que diferia de sua sucessora do século XX não simplesmente no que tinha a dizer acerca de substâncias e processos individuais, mas no modo por que estruturava e parcelava grande parte do mundo químico. (Kuhn 2006d, p.60)

Principia 17(1): 183-216 (2013). 
A intraduzibilidade parcial não nos impede de aprender a usar essas palavras 'princípio', 'elemento' e 'flogístico' — da maneira como elas eram usadas pelos adeptos da teoria do flogisto. Por essa razão, não impede a comunicação entre comunidades com taxonomias diferentes. É possível aprender a linguagem de uma taxonomia diferente, e isso torna o indivíduo que aprende bilíngue, mas não necessariamente tradutor. $^{25}$ Como afirma Kuhn,

[...] qualquer coisa que se possa ser dita em uma linguagem pode, com esforço e imaginação, ser compreendida por um falante de outra. O que é pré-requisito para uma tal compreensão, contudo, não é a tradução, mas a aprendizagem de uma linguagem. (Kuhn 2006e, p.81)

O ponto é que apesar de não ser possível uma tradução completa de termos de um léxico para a linguagem de outro, ainda assim é possível a comunicação, desde que os indivíduos aprendam a falar a linguagem dos diferentes léxicos.

No artigo "O caminho desde A estrutura" (Kuhn 2006c), a incomensurabilidade é apresentada como uma relação entre taxonomias lexicais, ou léxicos estruturados. Cada léxico pode produzir um leque de enunciados e teorias diferentes, mas há também enunciados que não pode expressar, embora possam sê-los em outro. Um exemplo é o enunciado copernicano "os planetas giram em torno do Sol" em contraste com o enunciado ptolemaico "os planetas giram em torno da Terra". Esse exemplo ilustra a diferença entre duas taxonomias, pois esses enunciados não são distintos simplesmente em relação aos fatos, mas em relação ao termo "planeta": a Terra não é um planeta no sistema ptolemaico. Nas palavras de Kuhn, "o termo planeta ocorre em ambos [os enunciados] como um termo para espécie, e os conjuntos dos membros das duas espécies se superpõem sem que nenhuma contenha todos os corpos celestes contidos nas outras". (Kuhn 2006c, p.120). Não é possível proferir os dois enunciados em um mesmo léxico sem violar o princípio de não-superposição de termos para espécie. Isso causaria um colapso de comunicação. Para evitar tal colapso é preciso que o indivíduo bilíngue - no sentido já expresso anteriormente lembre o tempo todo "qual léxico está em jogo, em qual comunidade está ocorrendo o discurso" (Kuhn 2006c, p.127).

\subsection{Críticas de Hacking à ênfase linguística da noção tardia de incomensurabilidade}

Como vimos, nos escritos tardios, Kuhn reformula a noção de incomensurabilidade de forma a enfatizar os aspectos linguísticos dessa noção explicando a dificuldade de comunicação entre léxicos distintos em termos de falha parcial de traduzibilidade interlexical. Ian Hacking (2009, caps 11 e 12), critica essa ênfase de Kuhn na noção de traduzibilidade. Para esse autor, aprender a traduzir ou a falar a linguagem de

Principia 17(1): 183-216 (2013). 
outro paradigma não é o aspecto central da compreensão mútua, mas sim a aprendizagem do estilo de raciocínio presente nos diferentes períodos da ciência. Estilo de raciocínio assemelha-se ao que era tratado por Kuhn como paradigma: "como o 'paradigma' de T. S. Kuhn, a palavra 'estilo' é empregada [...] para apontar para algo geral na história do conhecimento. Há novos modos de raciocínio que têm inícios e trajetórias específicas de desenvolvimento" (Hacking 2009, p.180). Estilo de raciocínio poderia ser definido, em termos gerais, como modos de pensar:

Parto do fato de que têm existido diferentes estilos de raciocínio científico. Os mais sábios dos gregos admiravam o pensamento euclidiano. As melhores mentes do século dezessete sustentavam que o método experimental colocava o conhecimento em uma nova base. Pelo menos uma parte de todas as ciências sociais modernas emprega um pouco de estatística. Exemplos como esses trazem à mente diferentes tipos de raciocínio com diferentes domínios. Cada um deles veio à tona e atingiu a maturidade em seu próprio tempo, de sua própria maneira. (2009, p.180)

Na história da ciência encontramos "diferentes estilos de raciocínio. [...] Eles surgem em pontos definidos e têm diferentes trajetórias de maturação. Alguns se extinguem, outros continuam a se fortalecer" (2009, p.196). As proposições que exigem necessariamente um raciocínio "são verdadeiras-ou-falsas apenas em consequência dos estilos de raciocínio nos quais ocorrem" (2009, p.196). Cada estilo de raciocínio envolve novidades, tais como "tipos de objetos, evidências, orações, novos modos de ser um candidato a verdade ou falsidade, leis, possibilidades" (2009, p.210). Assim, cada estilo de raciocínio científico traz com ele todos esses elementos.

Após uma transição de um estilo de raciocínio para outro, muitas das noções se tornam incompreensíveis. E essa incompreensão não seria adequadamente descrita em termos linguísticos, como Kuhn pretendeu fazer com sua noção tardia de incomensurabilidade:

Não é que as proposições [das ciências renascentistas] se encaixem mal com nossas ciências modernas, é mais que o modo como as proposições são propostas e defendidas é totalmente estranho para nós. É perfeitamente possível aprender o saber hermético, e quando você o aprende, acaba falando a língua de Paracelso, possivelmente em tradução. O que você aprende não são sistemas de tradução, mas cadeias de raciocínio que fariam pouco sentido, se a pessoa não estivesse recriando o pensamento de um daqueles magos. [...]

Entender o que é suficientemente estranho é uma questão de reconhecer novas possibilidades de verdade-e-falsidade, e de aprender como usar outros estilos de raciocínio que têm a ver com essas novas possibilidades. Conseguir chegar a um entendimento não é exatamente uma dificuldade de tradução, embora estilos estranhos tornem a tradução difícil. Não é certamente uma

Principia 17(1): 183-216 (2013). 
questão de fazer traduções que preservem tanta verdade quanto possível, porque o que é verdadeiro-ou-falso em um modo de falar pode não fazer muito sentido em outro até que a pessoa tenha aprendido a raciocinar de um novo modo. Um tipo de entendimento é aprender como raciocinar. Quando encontramos textos antigos ou muito estranhos, temos de traduzi-los, mas é errado nos concentrarmos naquele aspecto da tradução que meramente produz enunciados em inglês a partir de enunciados na outra língua. Com um foco tão limitado, a pessoa pensa em caridosamente tentar fazer com que o texto antigo diga tantas verdades quanto possível. Mas, mesmo depois de Paracelso ser traduzido para o alemão moderno, para entender o texto traduzido a pessoa ainda tem de aprender como ele raciocinava. (2009, p.191-2)

Assim, para Hacking, a compreensão das ciências antigas só ocorre ao aprendermos o seu modo de raciocinar. O ponto relevante para a compreensão dos modos de fazer ciência, não seria a tradução de uma linguagem científica para outra, pois "a comunicação de modos de pensar é o que interessa" (p.192), e não os modos de falar. Somente compreendendo o modo de pensar envolvido (o que se segue do quê, o que é indício do quê etc.) em uma época dada é que vamos compreender os objetos, problemas e soluções presentes nas investigações. Assim, descrever as mudanças históricas das ciências com ênfase em problemas de tradução seria errôneo: "a pessoa tem de aprender um modo de raciocinar", e uma vez feito isso, "não há mais qualquer problema de tradução" (p.192).

No entanto, não parece haver aqui incompatibilidade entre o que dizem Hacking e Kuhn. Os indícios que Kuhn apresenta para a incomensurabilidade são também indícios de estilos de raciocínio diferentes em Hacking. Aparentemente, a divergência principal entre esses autores é nominal apenas, e não substancial. Ela diz respeito ao que entendem por "tradução". Hacking, como vimos acima, afirma que temos boas (ou suficientemente boas) traduções de Paracelso e outros pensadores do passado para o nosso vocabulário contemporâneo. Mas certamente Kuhn não negaria isso. O que está em questão para Kuhn é a traduzibilidade das teorias de Paracelso (ou qualquer outro cientista do passado) para o vocabulário técnico das ciências contemporâneas, e não para uma linguagem contemporânea comum (o português contemporâneo, por exemplo). A tradução de um texto antigo para a linguagem técnica das ciências contemporâneas gera incoerências, e nesse sentido é sempre apenas parcial: as expressões técnicas das teorias do passado não encontram correlatos na linguagem técnica das ciências de hoje. Não há, por exemplo, nada que corresponda na química de hoje à expressão 'flogisto'. Nesse caso, Kuhn argumenta, a tradução sempre é parcial e falha, e precisa ser complementada por explicações (notas do tradutor, prefácios etc.) para tornar o texto compreensível (Kuhn 2006d, p.53). Todos os elementos daquilo que Hacking considera um estilo de raciocínio são considerados por Kuhn como relevantes para a produção de caos de incomensura- 
bilidade. $\mathrm{O}$ texto antigo precisa ser interpretado antes de ser traduzido, e parte do trabalho de interpretação não é propriamente incorporado ao texto traduzido, mas veiculado em explicações, notas introdutórias, comentários do tradutor etc. Assim, o que Kuhn considera relevante para a interpretação de teorias do passado são exatamente os elementos que Hacking considera relevantes para a compreensão de um estilo de raciocínio. ${ }^{26}$ Os casos que para Hacking evidenciam diferenças em estilos de raciocínio evidenciam para Kuhn falhas de tradução. O fenômeno em questão, no entanto, é o mesmo, e as abordagens de Kuhn e Hacking podem ser vistas como complementares.

\subsection{Incomensurabilidade como intraduzibilidade parcial: algumas considerações}

É evidente o esforço de Kuhn no sentido de refinar o conceito de incomensurabilidade após a Estrutura. Diferentemente de como o conceito foi apresentado na Estrutura, a saber, envolvendo incomensurabilidade entre os conceitos, problemas, métodos e padrões de solução de paradigmas distintos, agora ela é definida como intraduzibilidade local de termos centrais interdefinidos. É controverso, como vimos, se essa mudança diz respeito apenas à formulação ou se envolve modificação substancial no pensamento de Kuhn. A formulação da noção de fato é menos abrangente, pois a apresenta como intraduzibilidade parcial, focando a dificuldade de comunicação entre paradigmas distintos no colapso de linguagem que acontece se traduzirmos algumas frases (mas não todas) escritas em um léxico para frases escritas em outro. Isso não impede que haja comunicação entre os usuários de léxicos distintos, mas é necessário que cada qual aprenda a falar a linguagem do outro, isto é, tornem-se bilíngues. Isso, no entanto, exige bem mais do que apenas decorar certas palavras e associá-las a certos objetos e fenômenos. A interpretação de um léxico exige também que se aprenda a usar adequadamente um conjunto de princípios e leis da natureza, regras de inferência e uma série de outras habilidades que não são linguísticas em sentido estrito. Dessa maneira, embora a formulação da noção de incomensurabilidade nos textos tardios seja menos abrangente, isso não implica que o fenômeno descrito por essa noção seja menos abrangente ou menos rico. Seja como for, a reformulação da noção permitiu a Kuhn responder ou evitar as críticas à sua formulação anterior, segundo as quais paradigmas distintos são incomparáveis e que por isso não haveria como escolher racionalmente entre eles. A formulação tardia evita esse problema, pois fala apenas de incomensurabilidade local (intraduzibilidade de alguns termos apenas, não todos), e dessa maneira implica que a maioria dos termos continua funcionando da mesma forma antes e depois de uma revolução. Dessa maneira, não haveria um problema geral de incomparabilidade, como afirmaram os leitores iniciais da Estrutura. Além disso, as falhas localizadas de tra- 
dução entre léxicos distintos, não impedem a comunicação entre eles, pois a maioria dos termos são tratados da mesma maneira em ambos, e aqueles termos que não são intertraduzíveis podem ser aprendidos através da interpretação dos léxicos em questão.

\section{Critérios de decisão}

A descrição dos períodos de 'crise-revolução' na Estrutura, e em particular da escolha científica entre teorias rivais nesses períodos, gerou reações críticas fervorosas na década de 1960 e 1970 (ver Lakatos (1979 [1970]), Popper (1979 [1970]) e Laudan (2011 [1977]), por exemplo). Como vimos acima, Kuhn escreveu na Estrutura que a escolha científica não é apenas guiada por critérios lógicos e observacionais, mas também por fatores sociológicos, psicológicos, metafísicos e técnicas de persuasão internos à comunidade científica. Reagindo a isso, Lakatos chegou a dizer que as escolhas científicas, tal como descritas por Kuhn, seriam questões de "psicologia das multidões" (p.221). Para autores como Lakatos e Laudan, Kuhn descreveu de maneira excessivamente arbitrária os critérios de escolha entre teorias científicas nos períodos de revolução, fazendo parecer que nesses períodos a racionalidade científica falha ou que as escolhas não são objetivas.

Rejeitando críticas desse tipo, já no Posfácio da Estrutura, Kuhn apresenta como parte do que ele chamou de 'matriz disciplinar' (ver seção 1.3 acima) um conjunto de valores que são compartilhados pelos membros de uma comunidade científica, os quais são aprendidos pela prática científica e são preservados nos períodos de criserevolução como orientadores das escolhas entre paradigmas rivais. No entanto, não determinam a escolha de maneira unívoca, pois:

[...] esses valores podem ser compartilhados por homens que divergem quanto à sua aplicação. Julgamentos quanto à acuidade são relativamente, embora não inteiramente, estáveis de uma época a outra. Mas julgamentos de simplicidade, coerência interna, plausibilidade e assim por diante, variam enormemente de indivíduo para indivíduo. [...] nas situações onde valores devem ser aplicados, valores diferentes, considerados isoladamente, ditariam com frequência escolhas diferentes. Uma teoria pode ser mais acurada, mas menos coerente ou plausível que outra [...]. Em suma, embora os valores sejam amplamente compartilhados pelos cientistas e este compromisso seja ao mesmo tempo profundo e constitutivo da ciência, algumas vezes a aplicação dos valores é consideravelmente afetada pelos traços da personalidade individual e pela biografia que diferencia os membros do grupo. (Estrutura, Posfácio, p.232)

Em “Objetividade, juízo de valor e escolha de teoria” (2011 [1977]), Kuhn desenvolve melhor esse ponto, começando por destacar cinco características de uma boa

Principia 17(1): 183-216 (2013). 
teoria científica: precisão preditiva, coerência interna e externa, abrangência, simplicidade e fecundidade. Esses critérios são bastante usuais e difundidos. No entanto, sua aplicação é difícil, pois na escolha entre teorias rivais, cientistas comprometidos com os mesmos critérios podem chegar a resultados diferentes. Quando aplicados em conjunto, esses critérios podem conflitar. Por exemplo, uma teoria pode ser mais simples enquanto outra é mais abrangente. Nesse caso, a escolha dependerá do peso dado a cada critério, ou da interpretação que se dá a cada um. Não há uma regra que uniformize os procedimentos de decisão nesses casos, como pretenderam, por exemplo, Lakatos e Laudan. ${ }^{27}$

Kuhn entende que aqueles cinco critérios não são regras que determinariam univocamente uma escolha, mas valores que influenciam ou balizam as decisões. Isso permite que cientistas comprometidos com os mesmos valores façam escolhas diferentes em algumas situações, como de fato ocorre historicamente. Os valores não funcionam, portanto, como regras de aplicação unívoca, mas mesmo assim não deixam de guiar objetivamente as escolhas. Uma vantagem apontada por Kuhn, de se tomar aqueles critérios como valores é que fica então mais fácil de explicar aspectos do comportamento científico que haviam sido tomados pela tradição como anômalos (escolhas teóricas divergentes mesmo na presença de indícios observacionais e teóricos compartilhados). Outra vantagem é que a discordância no interior da comunidade científica é fundamental para que novas teorias possam surgir, o que não ocorreria se as regras ditassem univocamente uma única escolha, e não pudesse haver divergências quanto à melhor escolha. Do mesmo modo, justamente por discordarem, alguns cientistas permanecem trabalhando na teoria mais antiga permitindo que ela possa responder com "atrativos equivalentes" à sua rival. Assim, parece benéfico que os critérios funcionem como valores, pois isso distribui "o risco que sempre está envolvido na introdução de uma novidade, ou em sua manutenção" (2011 [1977], p.352). Isso, em outras palavras, é parte da "tensão essencial" que Kuhn vê como constitutiva da ciência.

O tema é retomado no artigo "Racionalidade e escolha de teorias" (Kuhn 2006e) e também no "Pós-escritos" (Kuhn 2006b). Nesse último, Kuhn discute a formulação de Ernan McMullin para o problema da racionalidade das escolhas, a saber, "qual é o processo por meio do qual têm lugar a proliferação e a mudança lexical, e em que medida se pode dizer que é governado por considerações racionais?” (Kuhn 2006b, p.306). Acerca desse problema, Kuhn afirma: “[...] embora creia que ela [a questão] demande reflexão e desenvolvimentos adicionais, a resposta fornecida na Estrutura ainda me parece ser a correta" (2006b, p.307). Em "Pós-escritos", Kuhn afirma que:

[...] estejam ou não cientes os praticantes individuais [da pesquisa científica], eles são treinados, e recompensados por isso, para resolver quebracabeças intrincados - sejam eles instrumentais, teóricos, lógicos ou matemáticos - na interface de seu mundo fenomenal com as crenças de sua

Principia 17(1): 183-216 (2013). 
comunidade a respeito dele. É isso o que eles são treinados a fazer e o que, na medida em que retenham o controle de seu tempo, fazem durante a maior parte de sua vida profissional. A grande fascinação que isso propicia - que, para os não iniciados, frequentemente parece uma obsessão — é mais do que suficiente para torná-lo um fim em si mesmo. Para os praticantes nenhum outro objetivo é necessário, embora os indivíduos com frequência elejam outros tantos. (Kuhn 2006b, p.307).

Se o empreendimento científico de resolução de quebra-cabeças é tomado como um fim em si mesmo, ou seja, como o próprio objetivo do empreendimento científico, então

[...] a racionalidade do rol usual de critérios para a avaliação da crença científica fica patente. Exatidão, precisão, alcance, fertilidade, consistência etc. simplesmente são os critérios que os solucionadores de quebra-cabeças devem sopesar ao decidir se determinado quebra-cabeça sobre a correspondência entre fenômenos e crenças foi ou não resolvido. Exceto por não precisarem ser satisfeitos todos de uma vez, são eles características 'definidoras' do quebra-cabeça resolvido. [...] Selecionar uma lei ou teoria que não lhes respondesse tão completamente como uma competidora existente seria contraditório em relação aos próprios objetivos da seleção, e uma ação autodesqualificante é o indicador mais seguro de irracionalidade. (Kuhn 2006b, p.307-8)

Os próprios valores gerados pelas práticas científicas são definidores do empreendimento e são esses os critérios empregados pra a avaliação do trabalho realizado durante o período em que há um léxico estruturado governando a pesquisa. No entanto, mesmo nos períodos de mudança lexical, esses valores permanecem igualmente básicos na avaliação das teorias emergentes. Como afirma Kuhn:

Empregados por praticantes treinados, esses critérios, cuja rejeição seria irracional, [...] são igualmente básicos para os mecanismos de resposta que, em períodos tensos, produzem especiação e mudança lexical. À medida que o processo evolucionário continua, exemplos pelos quais os praticantes aprendem a reconhecer exatidão, alcance, simplicidade etc. mudam tanto dentro de um campo quanto entre os campos. Mas os critérios que esses exemplos ilustram são, eles próprios, necessariamente permanentes, pois abandoná-los seria abandonar a ciência junto com o conhecimento trazido pelo desenvolvimento científico. (Kuhn 2006b, p.308)

Sendo assim, mesmo que mudem as práticas científicas após uma revolução científica, os critérios empregados nas avaliações das práticas nos períodos da ciência normal imediatamente anterior são retidos nesses períodos de transformação e permanecem guiando as escolha científicas, servindo então como uma base objetiva de avaliação das escolhas nesses períodos. ${ }^{28}$ Haveria, portanto, um descompasso entre as mudanças dos paradigmas ou léxicos e as mudanças de valores, e justamente 
esse descompasso permitira que as revoluções não fossem entendidas como momentos de irracionalidade científica. Durante um período de ciência normal a prática científica consagra certos tipos de práticas como modelares. Essas práticas, por sua vez, cristalizam-se na forma de valores que continuam guiando as atividades científicas mesmo quando o modelo de ciência que as originou entra em crise. Após a resolução da crise, um novo modelo de ciência é consagrado, que por sua vez traz consigo novas práticas que ao longo do tempo se cristalizarão em um novo conjunto de valores. Assim, embora os valores possam mudar ao longo da história da ciência, eles não mudam concomitantemente com os paradigmas ou léxicos, mas objetivamente balizam e orientam as escolhas de novos paradigmas ou léxicos durante as revoluções.

Como podemos ver, diferentemente das noções de incomensurabilidade e revolução científica, que foram notoriamente reformuladas nos escritos tardios, em relação aos critérios de decisão Kuhn mantém-se muito próximo do que já havia desenvolvido de maneira difusa na Estrutura (cap. 11) e de modo mais preciso no Posfácio da Estrutura. Lá ele já havia apresentado como parte do paradigma um conjunto de valores, os quais são importantes para julgar teorias distintas. No entanto, mesmo nas formulações tardias, Kuhn não avança muito nesse ponto, e continua apenas dando uma indicação geral de como funciona a presença de valores nas escolhas científicas, sendo eles capazes de preservar a objetividade (no sentido de que não são arbitrárias) das decisões sem necessitar que elas sejam de início unânimes. Assim, parece faltar um desenvolvimento pleno de como esses valores de fato operam nos períodos de revolução.

\section{Considerações finais}

De um modo geral, os textos tardios de Kuhn contêm ao menos duas características salientes em relação a suas obras inicias: em primeiro lugar, tendem a enfatizar o aspecto realista de seu pensamento, que caracteriza a atividade científica como guiada por critérios de escolha e valores objetivos compartilhados pela comunidade científica, opondo-se dessa maneira à reação inicial que a Estrutura provocou em seus leitores, especialmente nas décadas de 1960 e 1970. Em segundo lugar, as teses defendidas tendem a ser formuladas de maneira mais linguística. A noção de paradigma cede lugar à de léxico, a tese da incomensurabilidade é apresentada em termos de intraduzibilidade parcial e as revoluções científicas são descritas como mudanças nas categorias taxonômicas ou lexicais. Com relação ao primeiro ponto, de fato parece ter havido uma leitura apressada ou pouco caridosa da Estrutura por parte de sua primeira geração de leitores. Contudo, ao menos em parte, o próprio Kuhn pode ter sido responsável por isso, uma vez que algumas passagens se prestam

Principia 17(1): 183-216 (2013). 
a leituras relativistas ou psicologistas. Poderíamos, talvez, arriscar dizer que um dos fatores que levou a tantas interpretações controversas das teses defendidas na $E s$ trutura foi sua ênfase em negar muitas noções que eram até então compartilhadas e aceitas na literatura, como por exemplo a ideia de progresso cumulativo, que o progresso da ciência se faz por aproximação à verdade, que a escolha entre teorias rivais só seria racional se fosse o resultado da aplicação de regras objetivas (no sentido de algoritmos). Com relação ao segundo ponto, a formulação das teses de Kuhn em termos mais linguísticos parece ter produzido mais precisão conceitual, e, com isso, fornece as ferramentas necessárias para evitar ou responder as críticas de que suas teses implicavam em relativismo ou mesmo irracionalismo no empreendimento científico. Essas formulações mais linguísticas são também menos abrangentes, segundo o próprio Kuhn afirma. Mas não é claro se disso se segue que sejam menos ricas ou inadequadas para tratar dos fenômenos em questão (revolução científica, incomensurabilidade), como sugerem autores como Hacking. De fato, a noção de 'paradigma' da Estrutura, engloba não apenas compromissos teóricos explicitamente formuláveis em termos linguísticos, mas também práticas, comportamentos e modos de perceber a realidade que não se deixam claramente descrever em termos linguísticos. Esses aspectos da antiga noção de paradigma não fazem parte da formulação linguística de léxico, mas não são desconsiderados na obra tardia de Kuhn. A interpretação de um léxico exige que se considere não apenas a tradução verbal ou nominal das palavras que o compõem, mas também como são efetivamente usadas (isto é, as práticas, comportamentos e modos de perceber a realidade que tornam significativos o léxico em questão em um contexto histórico particular). Idem para a noção de incomensurabilidade local dos textos tardios: a sua formulação mais linguística (como intraduzibilidade parcial de um conjunto interdefinido de termos centrais de uma teoria) não considera explicitamente as diferenças metodológicas (campos de problemas e padrões de solução) e problemas perceptuais que compunham a noção de incomensurabilidade da Estrutura. Mas essas diferenças, segundo o próprio Kuhn afirma (como vimos acima: seção 2.1), decorrem do processo de aprendizagem da linguagem. A noção de linguagem que Kuhn emprega, portanto, é bem mais rica e substancial do que pode parecer à primeira vista - o que sugere que as diferenças entre o que ele e Hacking dizem sobre esse tema podem ser superficiais e não substanciais. $^{29}$

\section{Referências}

Bird, A. 2012. The structure of scientific revolutions and its significance: an essay review of the fiftieth anniversary edition. British Journal for the Philosophy of Science 63: 853-83. Chalmers, A. F. 1983. O que é ciência afinal? Trad. por Raul Fiker. São Paulo: Brasiliense. Dal Magro, T. 2012. Ciência e progresso. Crítica. Disponível em:

Principia 17(1): 183-216 (2013). 
http://criticanarede.com/progresso.html. Acesso em: 23 jun. 2013.

Davidson, D. 1974. On the very idea of a conceptual scheme. Proceedings and Addresses of the American Philosophical Association 47: 5-20.

Feyerabend, P. 1987. Putnam on incommensurability. The British Journal for the Philosophy of Science 38(1): 75-81.

Friedman, M. 2009. Kant, Kuhn e a racionalidade da ciência. Trad. Rogério Passos Severo. Philósophos 14(1): 175-209. Disponível em:

http://www.revistas.ufg.br/index.php/philosophos/article/view/8802\#.USJvzR03tDs. Acesso em: 10 out. 2012.

Fonseca, R. 2013. Aparência, presentação e objeto: Notas sobre a ambivalência de 'Erscheinung' na teoria kantiana da experiência. Studia Kantiana 14: 80-99. Disponível em: http://www.sociedadekant.org/studiakantiana/index.php/sk/article/view/130/130. Acesso em: 22 nov. 2013.

Godfrey-Smith, P. 2003. Theory and reality: an introduction to the philosophy of science. Chicago: The University of Chicago Press.

Irzik, G. 2012. Carnap e Kuhn: arqui-inimigos ou aliados próximos? Trad. por Gilson Olegario da Silva. Cognitio-Estudos 9(2): 269-89. Disponível em:

http://www.pucsp.br/pragmatismo. Acesso em: 15 maio 2013.

Hacking, I. 2002. Historical ontology. Cambridge, Mass.: Harvard University Press.

- 2012. Introductory essay. In: T. S. Kuhn, The structure of scientific revolutions. $4^{\text {th }}$ ed. Chicago: The University of Chicago Press.

Hoyningen-Huene, P. 1993. Reconstructing scientific revolutions. Chicago: The University of Chicago Press.

Hoyningen-Huene, P.; Oberheim, E. 2012. A incomensurabilidade das teorias científicas. Trad. por Laura Machado do Nascimento. Investigação Filosófica E2. Disponível em: http://investigacao-filosofica.blogspot.com.br/p/verbetes-da-enciclopediainvestigacao_8.html. Acesso em: 10/10/2012.

Kitcher, T. 1993. The advancement of science. Oxford: Oxford University Press.

Kuhn, T. S. 1978. Black-body theory and the quantum discontinuity. London: The University of Chicago Press.

_ 1979a. Lógica da descoberta ou psicologia da pesquisa? In: Lakatos; Musgrave (eds.) (1979a [1970]), p.5-32.

— 1979b. Reflexões sobre meus críticos. In: Lakatos; Musgrave (eds.) (1979b [1970]), p.285-343.

- 2001. A tensão essencial. Trad. por Marcelo Amaral Penna-Forte. São Paulo: UNESP.

- 2006. O caminho desde A estrutura. Trad. por Cezar Mortari. São Paulo: UNESP.

- 2006a. O que são revoluções científicas? In: Kuhn 2006, p.23-45.

- 2006b. Pós-escritos. In: Kuhn 2006, p.275-308.

- 2006c. O caminho desde A estrutura. In: Kuhn 2006, p.115-32.

- 2006d. Comensurabilidade, comparabilidade, comunicabilidade. In: Kuhn 2006, p.47-76.

- 2006e. Mundos possíveis na história da ciência. In: Kuhn 2006, p.77-114.

- 2006f. Racionalidade e escolha de teorias. In: Kuhn 2006, p.255-64.

—. 2006g. O problema com a filosofia histórica da ciência. In: Kuhn 2006, p.133-51.

Principia 17(1): 183-216 (2013). 
2011 [1962]. A estrutura das revoluções científicas. Trad. por Beatriz Vianna Boeira e Nelson Boeira. São Paulo: Perspectiva.

- 2011. Objetividade, juízo de valor e escolha de teoria. In: Kuhn 2011, p.339-59.

Lakatos, I. 1979. Falseamento e a metodologia dos programas de pesquisa científica. In: Lakatos; Musgrave (eds.) (1979 [1970]), p.109-243

—_ 1999 [1978]. Falsificação e metodologia dos programas de investigação científica. Trad. por Emília Picado Tavares Marinho Mendes. Lisboa: Edições 70.

Lakatos, I.; Musgrave, A. (eds.). 1979 [1970]. A crítica e o desenvolvimento do conhecimento. Trad. por O. M. Cajado. São Paulo: Cultrix.

Laudan, L. 2011 [1977]. O progresso e seus problemas: rumo a uma teoria do crescimento científico. Trad. por Roberto Leal Ferreira. São Paulo: UNESP.

Masterman, M. 1979. A natureza do paradigma. In: Lakatos; Musgrave (eds.) (1979[1970]), p.72-108.

Matheson, C. 2009. Historicist theories of rationality. The Stanford Encyclopedia of Philosophy. Disponível em http://plato.stanford.edu/archives/win2011/entries/rationalityhistoricist. Acesso em: 10/03/2013.

Mcmullin, E. 1979. Discussion Review: Laudan's Progress and its Problems. Philosophy of Science 46(4): 623-44.

Musgrave, A. 1979. Problems with Progress. Synthese 42(3): 443-64.

Popper, K. R. 1979. A ciência normal e seus perigos. In: Lakatos; Musgrave (eds.) (1979 [1970]), p.63-71.

Putnam, H. 1981. Reason, truth, and history. Cambridge: Cambridge University Press.

Sankey, H. 1990. In defence of untranslatability. Australasian Journal of Philosophy 68: 1-21. - 1993. Kuhn's changing concept of incommensurability. The British Journal for the Philosophy of Science 44: 759-74.

TAmires Dal Magro Programa de Pós-Graduação em Filosofia da Universidade Federal de Santa Maria. Rua Coronel Niederauer, 939, AP. 403

Santa Maria / RS. Bolsa de estudos (CAPES). tamiresdma@gmail.com

Resumo. Kuhn continuou produzindo filosofia de muito boa qualidade após A estrutura das revoluções científicas (1962), até seu falecimento em 1996. Este artigo descreve as mudanças em seu pensamento a respeito de três teses: (1) a de que o desenvolvimento da ciência não é cumulativo, (2) a de que paradigmas são incomensuráveis e (3) a de que a escolha de novos paradigmas nos períodos de revolução não se baseia apenas em observações e raciocínios lógicos. Essas três teses foram objeto de controvérsias na recepção inicial da obra de Kuhn, motivando fortes críticas à imagem da ciência alegadamente defendida pelo autor. Em resposta a essas críticas Kuhn enfatizou o aspecto realista de sua filosofia e reformulou em termos mais linguísticos as teses (1) e (2), mas deixou inalterada a tese (3). Argumentamos que as mudanças introduzidas em (1) e (2) tornaram as concepções de Kuhn mais precisas e menos abrangentes, e que a tese (3) não chegou a ser adequadamente desenvolvida.

Palavras-chave: Kuhn; revoluções científicas; incomensurabilidade; racionalidade científica.

Principia 17(1): 183-216 (2013). 


\section{Notas}

${ }^{1}$ Ver a esse respeito Hoyningen-Huene (1993), Godfrey-Smith (2003, p.75ss.), Bird (2012) e Hacking (2012), por exemplo.

${ }^{2}$ Ver, por exemplo, Kuhn $(1957,1978,2006 \mathrm{~g})$.

${ }^{3}$ Organizado por Lakatos e Musgrave (1970), e que reúne conferências de um simpósio sobre a Estrutura presidido por Popper em Londres, 1965.

${ }^{4}$ Leituras parecidas podem ser encontradas, por exemplo, em Laudan (2011 [1977]) e Chalmers (1983 [1976]). O primeiro diz que para Kuhn (e Feyerabend) "certas decisões entre teorias na ciência" não apenas "foram irracionais, mas [...] devem ser irracionais, por natureza" e "também sugeriram que todo ganho em conhecimento é acompanhado de perdas concomitantes, e assim é impossível afirmar quando, ou até mesmo se, estamos progredindo" (2011 [1977], p.6). Chalmers, por sua vez, na primeira edição de O que é ciência afinal? (1983 [1976]), dedicou uma seção inteira para falar de "Kuhn como relativista" (esse é o título da seção), o que reflete bem o modo como as concepções de Kuhn foram recebidas logo após a publicação da Estrutura. A seção termina assim: "a posição de Kuhn não deixa uma maneira de criticar as decisões e o modo de operação da comunidade científica. Enquanto a análise sociológica é básica dentro do relato de Kuhn, ela oferece pouca coisa à guisa de teoria sociológica e não oferece qualquer sugestão de como distinguir as formas aceitáveis e as inaceitáveis para se alcançar um consenso. [...] Kuhn negou que seu objetivo era dar um relato relativista da ciência, mas [foi o] que, contudo, ele nos deu" (1983 [1976], p.148). Na segunda edição dessa obra, de 1982, e também nas edições subsequentes, as seções que tratam de Kuhn foram modificadas. As críticas mencionadas acima foram excluídas do livro. Chalmers explica no prefácio à segunda edição (1983, p.15-6) que esses capítulos não eram claros e nem compostos por uma posição coerente ou bem argumentada, e que parte da culpa poderia ser atribuída a opiniões que estavam muito em voga na época em que o livro foi escrito.

${ }^{5}$ Ver, por exemplo, "Reflexões sobre meus críticos” (Kuhn 1979 [1970]), “Objetividade, juízo de valor e escolha de teoria" (Kuhn 2009 [1977]) e os artigos reunidos em O caminho desde A estrutura (2006) [doravante: $O$ caminho].

${ }^{6}$ Isso, ao menos, é o que Kuhn sugere: "Minha impressão, embora não seja mais do que isso, é que uma comunidade científica raro ou nunca adotará uma nova teoria a não ser que resolva todos os enigmas quantitativos e numéricos que se deparavam à sua predecessora. Por outro lado, eles sacrificarão o poder explanatório, deixando às vezes abertas questões anteriormente resolvidas e, às vezes, declarando-as inteiramente não-científicas." (1979a [1970], p.28-9)

${ }^{7}$ Posteriormente Kuhn reconsiderou o uso da expressão "pré-paradigmático". A alteração do conceito de paradigma, quando substituído pelas noções de "matriz disciplinar" e "exemplar" (ver o Posfácio da Estrutura, incluído na segunda edição, de 1970), diz Kuhn, "priva-me do recurso às expressões 'período pré-paradigmático' e 'período pós-paradigmático' quando descrevo a maturação de uma especialidade científica. Visto retrospectivamente, isto me parece muito bom, pois em ambos os sentidos do termo [paradigma], todas as comunidades científicas sempre possuíram paradigmas, incluindo as escolas do que denominei anteriormente 'período pré-paradigmático'. [...] [No entanto], essa alteração na terminologia não modifica de maneira alguma minha descrição do processo de maturação. Os primeiros estágios

Principia 17(1): 183-216 (2013). 
do desenvolvimento da maioria das ciências caracterizam-se pela presença de certo número de escolas concorrentes. Mais tarde, geralmente em decorrência de uma notável realização científica, todas essas escolas, ou o maior número delas, desaparecem, e a mudança faculta aos membros da comunidade restante um comportamento profissional muito mais vigoroso". (1979 [1970], p.335, nota 73). Sobre esse ponto, ver também Kuhn (1972).

${ }^{8}$ Uma das explicações de Kuhn da noção de paradigma diz que os trabalhos que serviram por um tempo para definir implicitamente os métodos e problemas científicos de um campo de pesquisa "puderam fazer isso porque partilhavam de duas características essenciais. Suas realizações foram suficientemente sem precedentes para atrair um grupo duradouro de partidários, afastando-os de outras formas de atividade científica dissimilares. Simultaneamente, suas realizações eram suficientemente abertas para deixar toda a espécie de problemas para serem resolvidos pelo grupo redefinido de praticantes da ciência [...] deverei referir-me às realizações que partilham essas duas características como 'paradigmas' " (Estrutura, p.30).

${ }^{9}$ Esse ponto foi criticado na literatura posterior, especialmente por Lakatos e Laudan. Nas palavras de Lakatos: “[...] de fato, o que ele [Kuhn] chama 'ciência normal' não é mais do que um programa de investigação que obteve monopólio. Mas, na realidade, os programas de investigação só raramente obtiveram o monopólio e, nesses casos, só por períodos relativamente curtos [...]. A história das ciências tem sido e devia ser uma história de competição entre programas de investigação (ou, se se preferir, 'paradigmas') [...]" (1999 [1978], p.80). Nessa mesma direção, Laudan afirma que "praticamente todos os grandes períodos da História da Ciência são caracterizados tanto pela coexistência de numerosos paradigmas concorrentes, com nenhum exercendo a hegemonia sobre o campo, quanto pela maneira persistente e contínua como as suposições fundamentais de cada paradigma são discutidas na comunidade científica" (1977, p.104-5). Ainda sobre esse ponto, Laudan ressalta que o modelo de Lakatos é uma melhora em relação ao de Kuhn porque "permite e ressalta a importância histórica da coexistência de diversos programas de pesquisa alternativos ao mesmo tempo, dentro da mesma área do saber" (p.108). Há passagens da Estrutura, no entanto, que podem ser interpretadas como satisfazendo essas considerações de Lakatos e Laudan. Kuhn diz, por exemplo, que "embora a mecânica quântica (ou a dinâmica newtoniana ou a teoria eletromagnética) seja um paradigma para muitos grupos científicos, não é o mesmo paradigma em todos os casos. Por isso pode dar origem simultaneamente a diversas tradições da ciência normal que coincidem parcialmente, sem serem coexistentes. Uma revolução produzida no interior de uma dessas tradições não se estenderá necessariamente às outras" (Estrutura, p.75); e que "as comunidades [científicas] podem certamente existir em muitos níveis. A comunidade mais global é composta por todos os cientistas ligados às ciências naturais. Em um nível imediatamente inferior, os principais grupos científicos profissionais são comunidades: físicos, químicos, astrônomos, zoólogos e outros similares [...] [Entre essas comunidades é possível] também isolar os principais subgrupos: químicos orgânicos (e, talvez entre esses, os químicos especializados em proteínas), físicos do estado sólido e de energia de alta intensidade, radioastrônomos e assim por diante. [...] De um ponto de vista típico, poderemos produzir comunidades de talvez cem membros e, ocasionalmente, de um número significativamente menor. Em geral os cientistas individuais, especialmente os mais capazes, pertencerão a diversos desses grupos, simultaneamente ou em sucessão" (Posfácio, p.223-4). Kuhn retoma esse ponto nos textos tardios: "Depois de uma revolução, geralmente são encontradas (talvez sempre existam) mais especialidades cognitivas ou campos de co-

Principia 17(1): 183-216 (2013). 
nhecimento do que havia antes: ou um novo ramo separou-se do tronco original, [...] ou então uma nova especialidade nasceu [...]. [O novo ramo] torna-se mais uma especialidade separada, gradualmente conquistando suas próprias novas revistas especializadas, uma nova sociedade profissional e, amiúde novas cátedras, laboratórios e, até mesmo, departamentos universitários. Ao longo do tempo, um diagrama da evolução dos campos, especialidades e subespecialidades científicas acaba parecendo-se espantosamente com um diagrama, feito por um leigo, de uma árvore evolutiva biológica. Cada um desses campos tem um léxico distinto, embora as diferenças sejam locais, ocorrendo apenas aqui e ali. Não há nenhuma língua franca capaz de expressar, em sua totalidade o conteúdo de todos eles, ou mesmo de algum par" (2006c, p.124). Embora essas passagens de Kuhn o aproxime das considerações de Lakatos e Laudan, não há nelas uma afirmação explícita ou mesmo uma sugestão clara de que há escolas ou programas concorrentes no interior de uma disciplina durante os períodos de ciência normal. Kuhn apenas sustenta que há disciplinas ou subdisciplinas que se ramificam após uma revolução.

${ }^{10}$ Margaret Masterman, no entanto, afirma que há três sentidos principais para a noção de 'paradigma' na Estrutura: (1) paradigma como uma visão de mundo (sentido metafísico); (2) paradigma como um conjunto de realizações científicas concretas, universalmente reconhecidas (sentido sociológico); e (3) 'paradigma de construção', isto é, um artefato ou um sistema que possibilita solução de problemas. Ao contrário de outros autores, ela sustenta que o sentido primário de 'paradigma' é o terceiro e não o primeiro, e que isso "permite [a Kuhn] estabelecer uma nova relação recíproca entre o emprego do modelo [ou paradigma no sentido de construção] e a metafísica. Pois em vez de perguntar 'Como é que um sistema metafísico pode ser usado como modelo?' [...] Kuhn pode perguntar agora: 'Como é que uma construção de solução de enigma (isto é, um paradigma no sentido 3) pode ser usado metafisicamente? Como é que um paradigma de construção pode, na verdade, transformar-se num 'modo de ver'?' " (1979 [1970], p.89). Sobre esse tópico, ver também Hoyningen-Huene (1993, p.131 ss.)

${ }^{11}$ Ver Estrutura (caps. 2, 4 e 8), Chalmers (1983, p.125-9), Godfrey-Smith (2003, p.77ss.), Hoyningen-Huene (1993, p.131-40) e Bird (2012).

${ }^{12}$ Sobre ciência normal, ver Estrutura, p.135-42, Hoyningen-Huene (1993, p.167-96) e Godfrey-Smith (2003, cap. 5).

${ }^{13}$ Sobre esse ponto, ao final da Estrutura, Kuhn diz que "a comunidade científica é um instrumento extremamente eficaz para maximizar o número e a precisão dos problemas resolvidos por intermédio da mudança de paradigma" (p.213). Em seguida, afirma que "nas ciências, não é necessário haver progresso de outra espécie. Para ser mais preciso, talvez tenhamos que abandonar a noção, explícita ou implícita, segundo a qual as mudanças de paradigma levam os cientistas e os que com eles aprendem a uma proximidade sempre maior da verdade" (p.215).

${ }^{14}$ Sobre esse ponto, ver Kuhn (2006g, p.139 s. e p.144-5).

${ }^{15}$ Ver Friedman (2009 [2002]), Kuhn (1979 [1970], Hoyningen-Huene (1993, p.230-5).

${ }^{16}$ Sobre os vários elementos envolvidos na escolha científica entre teorias rivais, ver Kuhn (2009 [1977]), Chalmers (1983, p.146-7) e Hoyningen-Huene (1993, p.252-7). Kuhn ilustra histórica e detalhadamente esses elementos na sua descrição da Revolução Copernicana (2002 [1957]) e (Estrutura, pp. 104, 110, 113-4, 153-4, 167). Ver também a descrição de Kuhn do surgimento da mecânica quântica (Kuhn, 1987 [1978]).

Principia 17(1): 183-216 (2013). 
17 Sobre esse ponto, ver Masterman (1979 [1970]), onde a autora afirma que "Kuhn, naturalmente, com seu estilo quase poético, torna a elucidação do paradigma autenticamente difícil para o leitor superficial. De acordo com a minha contagem, ele emprega a palavra 'paradigma' em ao menos vinte e um sentidos diferentes em seu 'The Structure of Scientific Revolutions'” (p.75).

${ }^{18}$ Algumas leituras de Kant que enfatizam o realismo empírico em sua filosofia parecem aproximá-lo daquilo que Kuhn entende por realismo. Para uma discussão desse ponto, e outras referências, ver Fonseca (2013).

${ }^{19}$ Embora Kuhn fale aqui de uma mudança de mundo, isso deve ser interpretado não em um sentido metafísico, mas prático: mudanças na estrutura lexical trazem consigo uma forma correspondentemente modificada de prática profissional e um diverso mundo profissional no qual conduzi-la. Um físico do século $X X$ pode entrar no mundo, digamos, da física do século XVIII ou da química do século XX. Mas esse físico não poderia exercer sua profissão em nenhum desses outros mundos sem abandonar aquele de onde veio (ver Kuhn 2006b, p.305 ss.).

${ }^{20}$ Essa ênfase nos aspectos linguísticos foi percebida por alguns autores como um equívoco. Hacking (2002, caps. 11 e 12), por exemplo, argumenta que os fenômenos relevantes não estariam propriamente nas linguagens ou léxicos usados pelas comunidades científicas, mas nos estilos de raciocínio adotados por elas.

${ }^{21}$ Ver Estrutura, cap. 9, p.147-54.

${ }^{22}$ Esse ponto é controvertido na literatura. Sankey (1993) defende a tese da intraduzibilidade de alguns termos centrais de paradigmas ou léxicos diferentes. Kitcher (1993), por outro lado, procura mostrar como até mesmo para esses termos centrais podem-se formular regras de tradução. Hacking (2002, caps. 11 e 12), por sua vez, prefere evitar tratar dos fenômenos relevantes a essa discussão como questões de tradução e prefere por isso evitar por completo a palavra 'incomensurabilidade'. Ele usa, em vez disso, as noções de 'estilo de raciocínio' e 'interpretação'.

${ }^{23}$ Ver também Hoyningen-Huene \& Oberheim (2012).

${ }^{24}$ Ver, por exemplo, Davidson (1974) e Putnam (1981).

${ }^{25}$ Sobre esse ponto, ver também Feyerabend (1987).

${ }^{26} \mathrm{Um}$ dos autores que influenciou Kuhn nesse ponto foi Fleck (ver Hoyningen-Huene \& Oberheim 2012), que já usava a noção de estilo de pensamento.

27 Sobre isso, ver Lakatos (1979 [1970] p.141-69), Laudan (2011 [1977] p.149-60), Kuhn (1979 [1970] p.293-8), Musgrave (1979), McMullin (1979), Matheson (2009), e Dal Magro (2012).

${ }^{28}$ Portanto, ao contrário do que sugere Friedman (2009), não é verdade que na concepção de Kuhn não haja critérios racionais pra escolha de novos paradigmas ou léxicos. Esses critérios existem, mas funcionam como valores que objetivamente balizam e orientam as escolhas sem determiná-las (como o fariam regras ou algoritmos). Friedman defende que é necessário para complementar a teoria de Kuhn a noção de metaparadigma, que forneceria critérios racionais de escolha de novos paradigmas. Mas talvez esse acréscimo à teoria de Kuhn seja desnecessário, se a concepção kuhniana sobre o papel dos valores na escolha de novos paradigmas for adequadamente desenvolvida.

${ }^{29}$ Agradecimentos: Rogério Passos Severo, Eros Moreira de Carvalho, Gilson Olegario da Silva, Laura Machado do Nascimento, Jonatan Willian Daniel e Marcelo Fischborn.

Principia 17(1): 183-216 (2013). 